\title{
Strategic Alignment in the Context of e-Services - An Empirical Investigation of the INSTAL Approach Using the Italian eGovernment Initiative Case Study
}

\author{
Gianluigi Viscusi ${ }^{1}$, Laure-Hélène Thevenet ${ }^{2,3}$, and Camille Salinesi ${ }^{2}$ \\ ${ }^{1}$ Department of Informatics, Systems and Communication (DISCo) \\ Università degli Studi di Milano-Bicocca - Italy \\ ${ }^{2}$ Centre de Recherche en Informatique, Université Paris 1 Panthéon-Sorbonne \\ 90 rue de Tolbiac 75013 Paris \\ ${ }^{3}$ BNP Paribas, Banque de Détail France - Informatique \\ 41 rue de Valmy 93100 Montreuil Sous Bois \\ viscusi@disco.unimib.it, laure-helene.thevenet@malix.univ- \\ parisl.fr, camille.salinesi@univ-parisl.fr
}

\begin{abstract}
Strategic alignment is an issue that is not just met in companies, but also in governments, governmental agencies and public administrations. This paper investigates the issues raised by strategic alignment in the context of eGovernment initiatives focused on e-services. The analysis reports a case study that explores the strategic alignment issue with the INSTAL method. Two facets are tackled: (a) the modeling of strategic alignment using a formal approach, and (b) the elicitation of evolution requirements based on the analysis of strategic alignment models.
\end{abstract}

Keywords: alignment model, strategic alignment, e-government, e-services.

\section{Introduction}

Strategic alignment (SA) of information systems (IS) is a primary concern arising from the eGovernment objectives in the context of the Italian health service. This paper investigates the INSTAL approach, which aims to model SA, analyse it, and elicit evolution requirements. The research question is how SA can be tackled in the eGovernment context and how the INSTAL approach can support the planning of e Government initiatives focused on design and development of e-services. Quality of services for the citizens is a major issue in the eGovernment context. Furthermore, quality is rarely considered in the SA perspective. Taking this into account, we explored the following hypotheses:

$<$ h1: The integration of strategic alignment and quality issues provides insights for the choice of suitable eGovernment initiatives $>$;

$<$ 2: Modeling strategic alignment helps eliciting evolution requirements for eGovernment initiatives $>$

The paper is organized as follows. Section 2 introduces the case study. Section 3 discusses the case study report. Section 4 concludes and gives perspectives. 


\section{Case Study Presentation}

In the initial situation, the Italian public administration (PA) is composed of central (e.g. ministries) and local agencies (about 8000). The organization is agency-centric processes, with little inter-agency, inter-organizational, and cross sector relationships. In particular, in the context of public health, information is rarely shared between different agencies, front offices and back offices. Citizens must make contact with local agencies to ask for agency-specific services. We focus in the rest of this paper on the health services and in particular on the process of changing family doctors.

In the initial situation, health care services faced difficulty in fulfilling users' demand, due to the bureaucratic procedures and PAs organization. In Italy, any citizen must have a family doctor. To choose one, citizens have to (i) make the request to the health PA of residency (at opening time), (ii) exhibit their health card, and (iii) proceed to the choice of a doctor (in the area). Several certificates are asked. For citizens who do not live in the area of the health center, a specific committee has to decide. For foreign citizens with no residency, the choice of doctor can be valid from three months to a year and renewable; in the case of residents the choice is valid for a year and automatically renewed. In 2002, a plan was initiated to change the initial PA organization for service provision, by having a user oriented perspective and developing online services.

\section{Case Study Report}

This section reports how the INSTAL (Intentional Strategic Alignment) method [1] was applied on the case study of the Italian eGovernment.

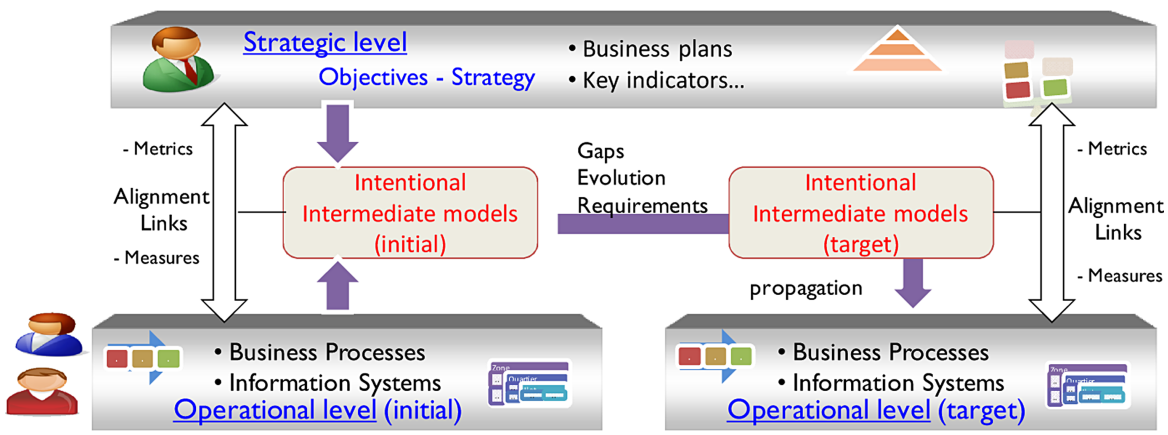

Fig. 1. INSTAL overview

As shown in Fig. 1, the main characteristics of the INSTAL method are: (1) to model strategic alignment intentions at an intermediate level (SA maps), and (2) to define strategic alignment links between strategic and operational elements. In INSTAL, only elements that share a same intention can be aligned and thus a SA link modeled. Metrics (at strategic level) and measures (at operational level) can also be attached to SA links to provide a quantitative assessment of SA. The map formalism 
was used at the intermediate level because (1) it is intentional and (2) it allows tackling the variability within and between the two levels.

As shown in [1], to define SA maps, we searched for public administration issues (e.g. increasing reliability, decreasing cost; attaining the most users, avoiding redundant activities), qualities (that should be increase, e.g.: availability, accessibility, ease of use, transparency) and resources (that should be controlled, e.g. dematerialized data, time, complexity control, competencies) in strategic and operational elements. The SA map presented in Fig. 5 was first specified, it represents the Italian eGovernment strategy under the perspective of its implementation at the operational level. A SA map is drawn according to the MAP formalism [3]. Two main goals are presented in this map: (b) Increase the access quality of service and (c) Maintain data. These goals are ambivalent. Indeed, they can represent the organization's strategy but also tackle the operational level. The goal (b) Increase the access quality to service is an important goal that justifies the strategy undertaken. Access quality covers availability, accessibility, ease of use etc. The other important goal is (c) Maintain data, since every service is based on data. Data is the main resource specifically provided by eGovernment to citizens.

(1) By workflow monitoring

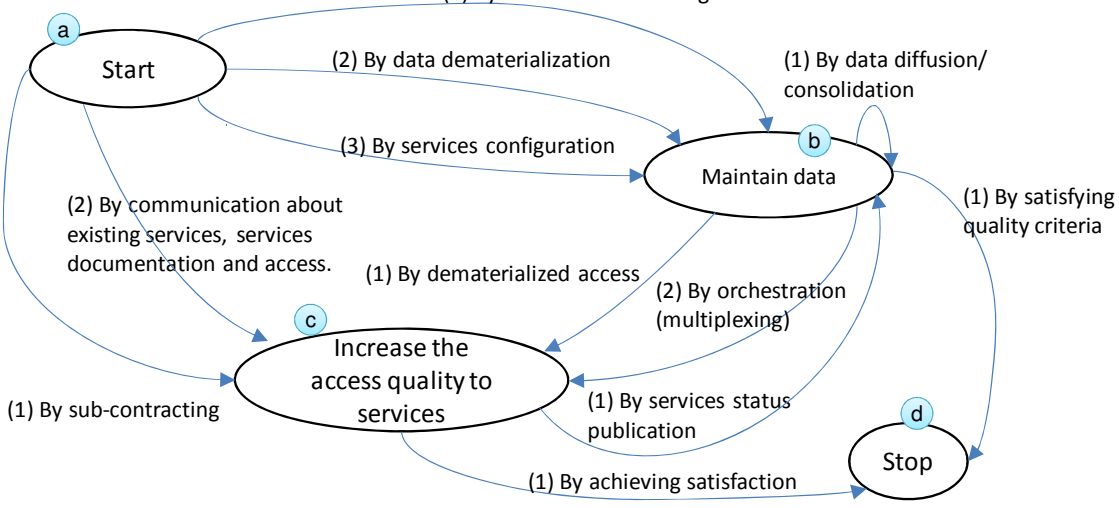

Fig. 2. SA map "Improve accessibility to Italian Public Administration Services"

For the sake of space, we do not present the eleven SA links attached to the sections. Each one is named by the section it relates to (i.e. the target goal and strategy behind the link), and is defined between the eGovernment strategy and the operational elements in order to detect the cases of good alignment and misalignment. For example, elements of the initial business process for changing doctors are involved in some SA links with a contradictory role. In fact, the SA link relating to the section ab2 (maintain data by data dematerialization) involves the business process with a contradictory role since any exchange of data is paper-based. The analysis of elements roles as well as the new SA requirements makes emerge evolution requirements. Moreover, we used three quality level criteria (defined in [2]): the temporal, economic, and procedural efficiency, to uncover metrics completing the initial SA link models. To each metric is associated a current and a target value that characterize how the SA should be reached in the future. For example, the service time available is currently 30 hours 
a week, whereas the required value is 72 hours a week. Based on SA models and SA links analysis (with attached metrics), evolution requirements can be found, such as:

- A health-website at a regional level should provide most important health services to citizens and businesses (no more restricted to the services available in local agencies), even if requests can be made on different channels such as Internet and local agencies.

- A multichannel strategy oriented to users should be adopted (e-mail center, call center, authoring system). For the change of doctor request, citizens can make requests on the Internet, download certificates if needed, and follow the status of their request (by status notification, by email) etc.

- Information sharing between all health organizations. For the change of doctor request, citizens do not have to provide documents. Health system (in local agencies or by internet) can search information (automatically and transparently to user) by IT services, etc.

\section{Conclusion}

This paper explored the issue of developing services by analyzing their alignment with strategic Italian eGovernment objectives. This case study has shown: (i) SA models enriched with quality issues provide a purposeful view on alignment (confirming $h 1$ ), (ii) SA models can be used as a central point to draw and organize complex SA links between organization elements (confirming $h l$ ), (ii) roles of SA links can be used to analyze initial SA and identify evolution requirements (confirming $h 2$ ). However, a more complete evaluation should be carried out, one that more specifically considers other eGovernment initiatives (in the same and other countries), and also focuses on the interactions with businesses in the private sector. Future work is to consider: (i) studying the difference between public and private sector and if needed adapt the INSTAL method; (ii) integrating a social facet in the SA model to understand the social impact of the new services, and to facilitate their adoptions.

\section{Acknowledgements}

The research work has been partially supported by the Italian FIRB project NeP4B.

\section{References}

1. Thevenet, L.-H., Salinesi, C.: Aligning IS to Organization's Strategy: The INSTAL Method. In: Krogstie, J., Opdahl, A., Sindre, G. (eds.) CAiSE 2007 and WES 2007. LNCS, vol. 4495, pp. 203-217. Springer, Heidelberg (2007)

2. Viscusi, G., Batini, C., Cherubini, D., Maurino, A.: A Quality Driven Methodology for eGovernment Project Planning. RCIS:97-106 (2007)

3. Rolland, C.: Capturing System Intentionality with Maps. In: Krogstie, J., Opdahl, A.L., Brinkkemper, S. (eds.) Conceptual Modelling in Information Systems Engineering. Springer, Heidelberg (2007) 